Article

\title{
SimCP3-An Advanced Homologue of SimCP2 as a Solution-Processed Small Molecular Host Material for Blue Phosphorescence Organic Light-Emitting Diodes
}

\author{
Yi-Ting Lee ${ }^{1}$, Yung-Ting Chang ${ }^{2}$, Cheng-Lung $\mathrm{Wu}^{2}$, Jan Golder ${ }^{3}$, Chin-Ti Chen ${ }^{2,3, *}$ \\ and Chao-Tsen Chen ${ }^{1, *}$ \\ 1 Department of Chemistry, National Taiwan University, Taipei 10617, Taiwan; likewithyou@gmail.com \\ 2 Institute of Chemistry, Academia Sinica, Taipei 11529, Taiwan; eveningtin@gmail.com (Y.-T.C.); \\ cdstant@yahoo.com.tw (C.-L.W.) \\ 3 Department of Applied Chemistry, National Chiao Tung University, Hsinchu 30050, Taiwan; \\ jangolder@gmx.net \\ * Correspondences: chintchen@gate.sinica.edu.tw (C.-Ti Chen); chenct@ntu.edu.tw (C.-Tsen Chen); \\ Tel.: +886-2-2789-8542 (C.-Ti Chen); +886-2-3366-4200 (C.-Tsen Chen)
}

Academic Editor: Jwo-Huei Jou

Received: 5 September 2016; Accepted: 27 September 2016; Published: 30 September 2016

\begin{abstract}
We have overcome the synthetic difficulty of $9,9^{\prime}, 9^{\prime \prime}, 9^{\prime \prime \prime}, 9^{\prime \prime \prime \prime}, 9^{\prime \prime \prime \prime \prime}-(($ phenylsilanetriyl) tris(benzene-5,3,1-triyl))hexakis(9H-carbazole) (SimCP3) an advanced homologue of previously known SimCP2 as a solution-processed, high triplet gap energy host material for a blue phosphorescence dopant. A series of organic light-emitting diodes based on blue phosphorescence dopant iridium (III) bis(4,6-difluorophenylpyridinato)picolate, FIrpic, were fabricated and tested to demonstrate the validity of solution-processed SimCP3 in the device fabrication.
\end{abstract}

Keywords: solution process; molecular host material; high triplet gap energy; SimCP2; blue phosphorescence OLED

\section{Introduction}

An increasing number of high-performance blue phosphorescence organic light-emitting diodes (OLEDs) can be found in literature reports. Although remarkable electroluminescence (EL) efficiency as high as $\sim 27 \%, \sim 51 \mathrm{~lm} / \mathrm{W}$, or $\sim 54 \mathrm{~cd} / \mathrm{A}$ based on sky-blue phosphorescence dopant iridium (III) bis(4,6-difluorophenylpyridinato)picolate (FIrpic) has been achieved [1-7], vacuum-thermal-evaporation is a common device fabrication process, but it is not favorable for mass production or large panel fabrication. Accordingly, for more desirable production or fabrication process, there have been a number of solution-processable small molecular host materials for blue phosphorescence organic light-emitting diodes in recent years [8-14]. We and others have developed and demonstrated bis(3,5-di(9H-carbazol-9-yl)phenyl)diphenylsilane (SimCP2 in Scheme 1) as one of high-performance solution-processable small molecular host materials for yellow, green, and blue phosphorescence OLEDs [15-22]. More recently, SimCP2 hosted FIrpic OLEDs were reported as having EL efficiency reaching $11 \%, \sim 11 \mathrm{~lm} / \mathrm{W}$, or $23 \mathrm{~cd} / \mathrm{A}$ [23]. Nevertheless, the EL of these FIrpic OLEDs with solution-processed light-emitting layer is far less efficient than those OLEDs fabricated by vacuum-thermal-evaporation. For blue phosphorescence OLEDs, solution-processable small molecular hosts with a high triplet energy gap $\left(E_{\mathrm{T}}\right)$ greater than $2.6 \mathrm{eV}$ of the benchmark sky-blue FIrpic are still rare and highly demanded in the field. As our ongoing effort to develop high-performance solution-processable small molecular host materials 
for blue phosphorescence OLEDs, we have recently overcome synthetic difficulties and successfully prepared 9,9', $99^{\prime \prime}, 9^{\prime \prime \prime}, 9^{\prime \prime \prime \prime}, 9^{\prime \prime \prime \prime \prime \prime}$-((phenylsilanetriyl)tris(benzene-5,3,1-triyl))hexakis(9H-carbazole) (SimCP3) (Scheme 1) as an advanced homologue of SimCP2. Herein, we report the synthesis and characterization of SimCP3 in full detail. A series of SimCP3-hosted OLEDs are fabricated and tested to demonstrate its viability as a solution-processed host material for sky-blue phosphorescence OLEDs.

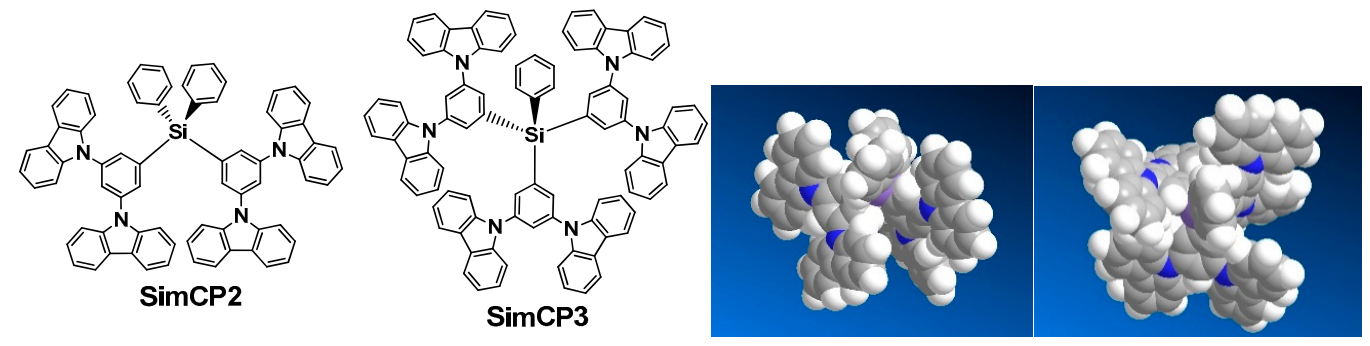

Scheme 1. Chemical structure of SimCP2 and SimCP3. MM2 energy minimized structures (by Chem 3D) are shown on the right, respectively.

\section{Results and Discussion}

In our earlier reports [16,24,25], both 9,9'-(5-(triphenylsilyl)-1,3-phenylene)bis(9H-carbazole) (SimCP) and SimCP2 were synthesized in a similar method (Scheme 2). Either chlorotripheylsilane or dichlorodiphenylsilane was reacted with monolithiated 1,3,5-tribromobenzene to furnish 1,3-dibromophenyl substituted thriphenylsilane and bis-1,3-dibromophenyl substituted diphenylsilane, respectively. The silane compounds were then brought to a palladium-catalyzed amination reaction with excess amount of carbazole. Both SimCP and SimCP2 were obtained with a reasonable isolation yield of $54 \%$ and $\sim 40 \%$, respectively, in the final amination reaction. It is conceivable that the reaction yields will be lower than that of SimCP2 if the higher homologue SimCP3 is prepared by a same reaction sequence shown in Scheme 2.

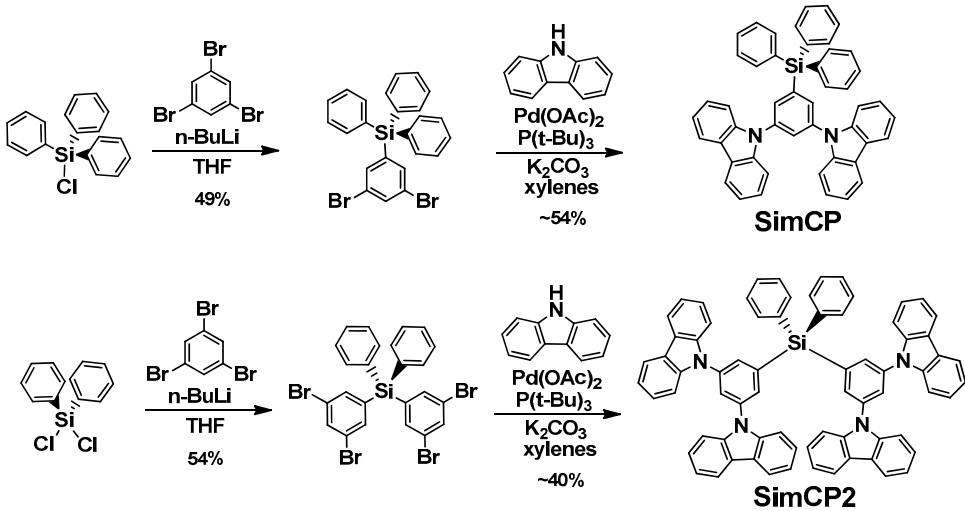

Scheme 2. Synthetic preparation of SimCP and SimCP2.

Due to the much more partial amination products formed in the reaction of synthesizing SimCP3, we obtained a series of product mixtures, which were hard to separate by column chromatography. In addition, the purification of SimCP3 required a tedious process in order to remove the excess amount of carbazole used in the reaction. Alternatively, we have been able to synthesize SimCP by using mono-lithiated 9,9'-(5-bromo-1,3-phenylene)bis $(9 H$-carbazole) (BrmCP) to react with chlorotripheylsilane. However, the same synthetic approach has been problematic in the preparation of SimCP2 and SimCP3, even though a very recent literature has reported the same synthetic approach in the preparation of SimCP2 and SimCP3 [23]. We also tried the approach of Grignard reaction ( $\mathrm{Mg}$ instead of $n$-butyllithium), but it did not work out well either. It seems to us 
that either lithiated or magnesiated BrmCP is relatively unstable under the reaction condition. In the case of SimCP2 and SimCP3, the chance of either lithiated or magnesiated BrmCP reacting more than once with dichlorophenylsilane or trichlorophenylsilane is rather low. In addition, the reaction is quite sensitive to the purity of dichlorophenylsilane or trichlorophenylsilane, which is prone to hydrolysis and generates hydrochloric acid that is detrimental to the reaction. Finally, we were able to synthesize and isolate pure SimCP3 in multi-gram scale via reaction with sodium metal, i.e., a Würtz-Fittig-type coupling reaction between chlorosilane and aryl halide (Scheme 3) [26,27]. Instead of a carbon anion of BrmCP, a more feasible silyl anion of trichlorophenylsilne is involved in the coupling reaction.

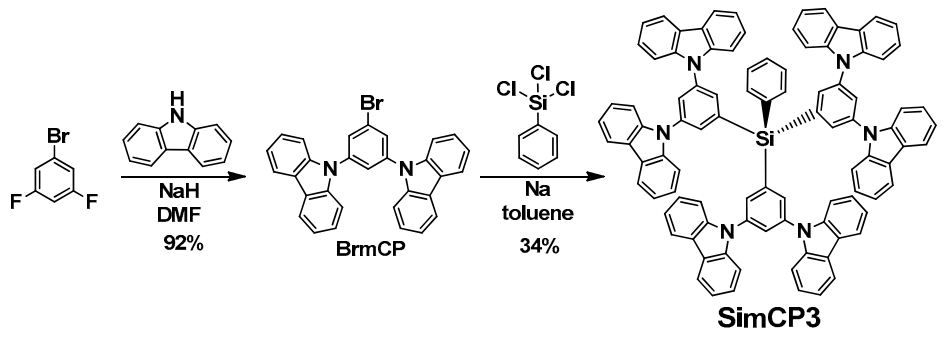

Scheme 3. Synthesis of SimCP3 from BrmCP via Würtz-Fittig reaction.

To facilitate the SimCP3 preparation, we improved the synthesis of BrmCP with a significantly better isolation yield of $>90 \%[12,28]$. Regarding the Würtz-Fittig-type coupling reaction, SimCP3 was furnished in only modest yields around 30\% due to the competition reaction of the potential silicon-silicon bond formation of oligosilane or polysilane [29,30]. However, the desired product was much easier to isolate from the product mixture. In this reaction, we also observed silanol side products, although they were readily removed by column chromatography. In addition, there was no excess amount of carbazole involved in the reaction; hence, no extra purification process was required for SimCP3. These are the main advantages of the Würtz-Fittig reaction over other synthetic methods of preparing SimCP3. Several spectroscopic and physical methods were used to characterize the homogeneity of thin film and the necessary optoelectronic properties of SimCP3 as a solution-processable host material for FIrpic OLEDs.

First, as shown in Figure 1, SimCP3 is very thermally stable with a thermal decomposition temperature $\left(T_{\mathrm{d}}\right)$ as high as $620^{\circ} \mathrm{C}$, where $5 \%$ weight loss was determined by thermogravimetric analysis (TGA) under a nitrogen atmosphere. Second, SimCP3 exhibits amorphous or semi-amorphous characteristic based on the thermograms of differential scanning calorimetry (DSC). As shown in Figure 1, SimCP3 has melting temperatures $\left(T_{\mathrm{m}}\right)$, crystallization temperatures $\left(T_{\mathrm{c}}\right)$, and glass transition temperatures $\left(T_{\mathrm{g}}\right)$ of 330,223 , and $174{ }^{\circ} \mathrm{C}$, respectively. Two very weak exothermic signals around 290 and $330^{\circ} \mathrm{C}$ may be the inhibited crystallization process of thermally annealed SimCP3. The $T_{\mathrm{m}}$ and $T_{\mathrm{C}}$ of SimCP3 disappeared, and $T_{\mathrm{g}}$ was observed after the first heating scan, indicative of the amorphous tendency of SimCP3.

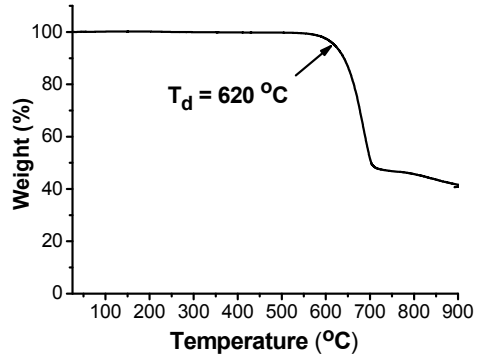

(a)

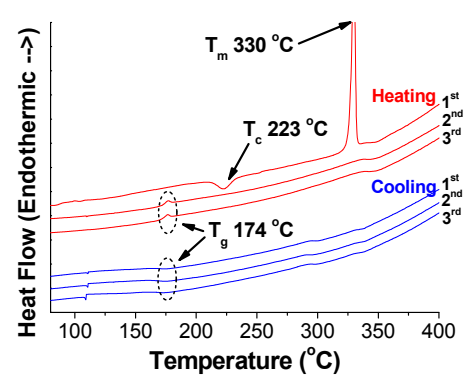

(b)

Figure 1. TGA (a) and DSC (b) thermograms of SimCP3. 
Similarly, amorphous or semi-amorphous characteristics are evident from the X-ray diffraction (XRD) spectrum (Figure 2a) of the solution-casting thin film of SimCP3. The XRD spectrum is basically a featureless halo, indicative of an amorphous nature. Macroscopically, the homogeneity of the solution spin-coated SimCP3 thin film is evident from the photoluminescence (PL) images of the neat film and FIrpic-doped SimiCP3 thin films (Figure 2b), which show uniform color and no sign of agglomeration or phase separation. Microscopically, atomic force microscopy (AFM) demonstrated the homogenous and flat surface morphology of SimCP3 thin films with or without a FIrpic dopant (Figure 3). Whereas thin film of poly(3,4-ethylenedioxythiophene) doped with poly(styrenesulfonate) (PEDOT:PSS) had a higher surface roughness of $0.68 \mathrm{~nm}$, a rather small values of root-mean-square (RMS) roughness of 0.25 and $0.33 \mathrm{~nm}$ was observed for the thin film of SimCP3 and SimCP3:FIrpic (10 wt \%), respectively. Regarding the flatness of the thin films, none of the discernable features in AFM surface images had a height over $5.5 \mathrm{~nm}, 2.1 \mathrm{~nm}$, and $2.7 \mathrm{~nm}$, for PEDOT:PSS, SimCP3, and SimCP3:Firpic thin films, respectively.
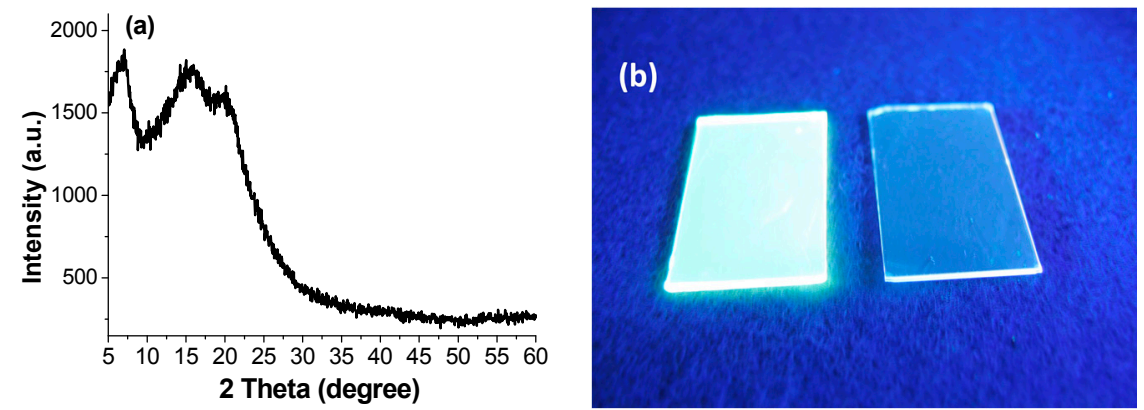

Figure 2. (a) XRD spectra of the solution drop-casting thin film of SimCP3 on silicon wafer; (b) PL images of solution spin-coated thin films of SimCP3: FIrpic $(\sim 10 \mathrm{wt} \%)$ and SimCP3.

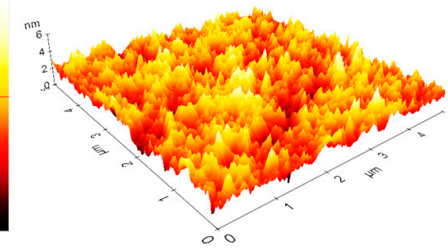

(a)

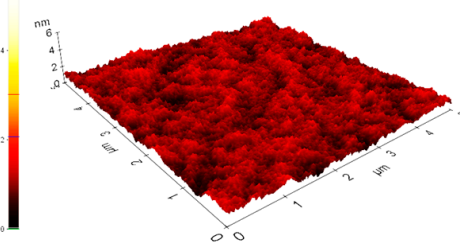

(b)

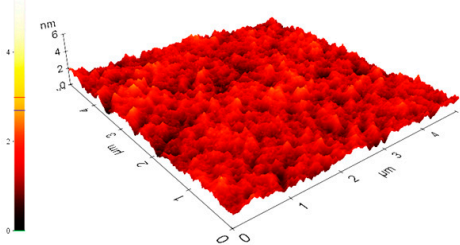

(c)

Figure 3. $5 \times 5 \mu \mathrm{m}$ AFM images of ITO/PEDOT:PSS (a); ITO/PEDOT:PSS/SimCP3 (b); and ITO/PEDOT:PSS/SimCP3:FIrpic (10 wt \%) (c).

The most important property of the host material for a blue phosphorescence dopant such as FIrpic is $E_{\mathrm{T}}$. We estimated the $E_{\mathrm{T}}$ of SimCP3 as a neat thin film with time-gated acquisition PL spectra at low temperatures (Figure $4 a, b$ ). From spectra with either variable delayed time or variable low temperature, it can be confirmed that the emission band with a $\lambda_{\max }$ around $400 \mathrm{~nm}$ is the delayed fluorescence and a $\lambda_{\max }$ around $525 \mathrm{~nm}$ is the phosphorescence. By taking the onset wavelength of the high energy edge of phosphorescence bands, we obtain $\sim 461-468 \mathrm{~nm}(2.69-2.65 \mathrm{eV})$ as the optical energy gap for $E_{\mathrm{T}}$. From our measurements, the $E_{\mathrm{T}}$ of SimCP3 is sufficiently larger than that of FIrpic, ensuring triplet state exciton on the phosphorescence dopant rather than its host SimCP3. The UV-visible absorption and fluorescence spectra of SimCP3 in solution are illustrated in Figure 4c. 

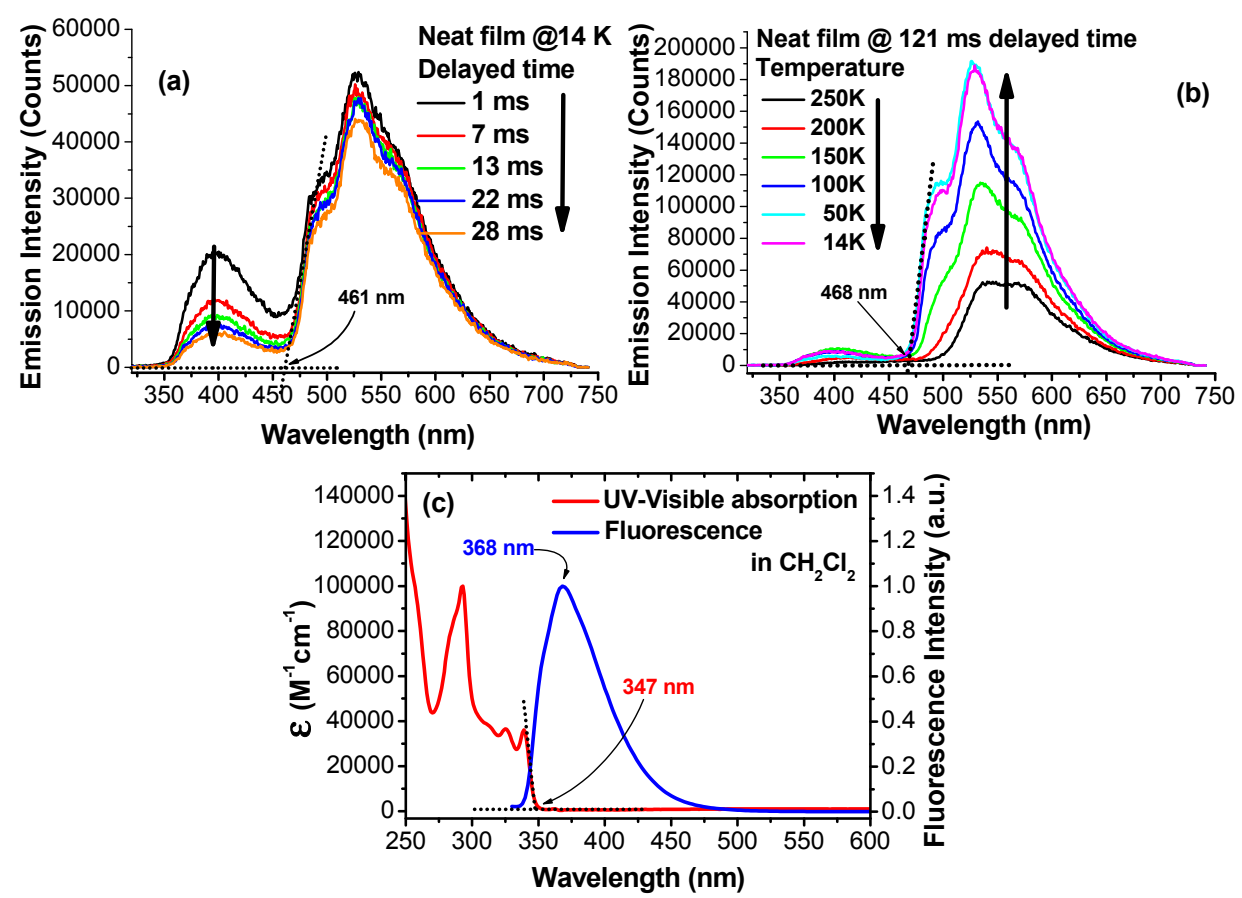

Figure 4. (a) Variable time-gated PL spectra of SimCP3 thin film; (b) Variable temperature, $121 \mathrm{msec}$ time-delayed PL spectra of SimCP3 thin film; (c) Room temperature absorption and PL spectra of SimCP3 in dichloromethane solution.

Knowing an optical energy gap of $3.57 \mathrm{eV}$ (347 nm shown in Figure 4c) and the HOMO energy level of $5.95 \mathrm{eV}$ (Figure 5a), which was acquired by a low-energy photoelectron spectrometer Riken-Keiki AC-2, the LUMO energy level of SimCP3 can thus be calculated as $\sim 2.4 \mathrm{eV}$. Together with the HOMO and LUMO energy levels and $E_{\mathrm{T}}$ of TAPC (hole transporting or electron blocking material) [31,32], FIrpic [32], and TmPyPB (electron transporting or hole blocking material) [33], the energy level alignment of materials involved in OLEDs is depicted in Figure 5b. Therefore, TAPC, SimCP3, and TmPyPB all have HOMO and LUMO energy levels that encompass those of FIrpic, and FIrpic has the smallest $E_{\mathrm{T}}$ among all materials involved in the OLED fabrication. This is a good set of materials enabling the confinement of triplet exciton on the FIrpic phosphorescence dopant. Accordingly, we fabricated three types of FIrpic OLED having SimCP3 as a solution-processed host material: a single-layer device (SL)—ITO/PEDOT:PSS/SimCP3:FIrpic/CsF/Al—a bilayer device (BL)—ITO/PEDOT:PSS/SimCP3:FIrpic/TmPyBP/CsF/Al—and a trilayer device (TL)—ITO/ PEDOT:PSS/TAPC/SimCP3:FIrpic/TmPyBP/CsF/Al. After optimization, the dopant concentration of FIrpic was $4 \mathrm{wt} \%$ in all three devices. Except for TmPyBP and CsF/Al cathode, each thin film layer of such FIrpic OLEDs was fabricated by solution process, i.e., the spin-coating method.
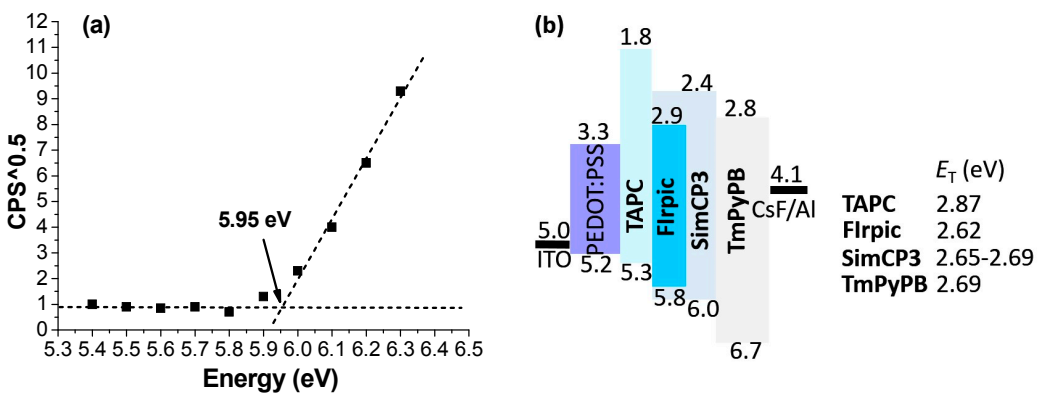

Figure 5. (a) Low-energy photoelectron spectra of SimCP3; (b) Energy level alignment of materials involved in OLEDs. 
EL characteristics of SL, BL, and TL devices are summarized in Figure 6 and Table 1. All three devices exhibit typical sky-blue emissions of FIrpic with a $\lambda_{\max }$ of $\sim 468 \mathrm{~nm}$, although a variation of emission shoulder band around $500 \mathrm{~nm}$ (Figure 6a) was observed. Since both BL and TL devices have a similar intensity of the shoulder band and are both more intense than that of the SL device, it can be logically inferred that TmPyPB effectively blocks the triplet exciton of FIrpic, confining the charge recombination mostly in the SimCP3:FIrpic light-emitting layer (i.e., farther away from the cathode surface) [19]. Therefore, the same reason can be ascribed to the low EL efficiency of the SL device (Figure $6 b, c$ ), where the triplet exciton of FIrpic generates in an area too close to the cathode surface and hence is prone to being quenched. Similarly, the TAPC of the TL device plays a role of inhibiting triplet exciton from contacting the anode of the device. Therefore, the EL efficiency of the TL device is promoted further when compared with the BL device. The maximum external quantum efficiency (EQE), current efficiency (CE), and power efficiency (PE) of the TL device are 9\%, $\sim 20 \mathrm{~cd} / \mathrm{A}$, and $12 \mathrm{~lm} / \mathrm{W}$, respectively. However, the TL device has the lowest current density and the highest turn-on voltage-around $5 \mathrm{~V}$ at $1 \mathrm{~cd} / \mathrm{m}^{2}$ (see Figure $6 \mathrm{~d}$ ) —among the three devices. This can be attributed to the two exciton blocking layers in the device, which limits the current density and elevates the driving voltage of the device. Nevertheless, all three devices exhibited relatively mild efficiency roll-off. Even at the high brightness of $3000 \mathrm{~cd} / \mathrm{m}^{2}$ (about 38,30 , and $19 \mathrm{~mA} / \mathrm{cm}^{2}$ of the SL, $\mathrm{BL}$, and TL devices), an EQE of $3.6 \%, 4.5 \%$, and $7.4 \%$ were achieved by the SL, BL, and TL devices, which are $95 \%, 62 \%$, and $81 \%$ of the maximum EL efficiency, respectively (Figure 6c). Compared with those of vacuum-thermal-evaporation OLEDs [2,4], the efficiency roll-off observed for the three devices is relatively modest.
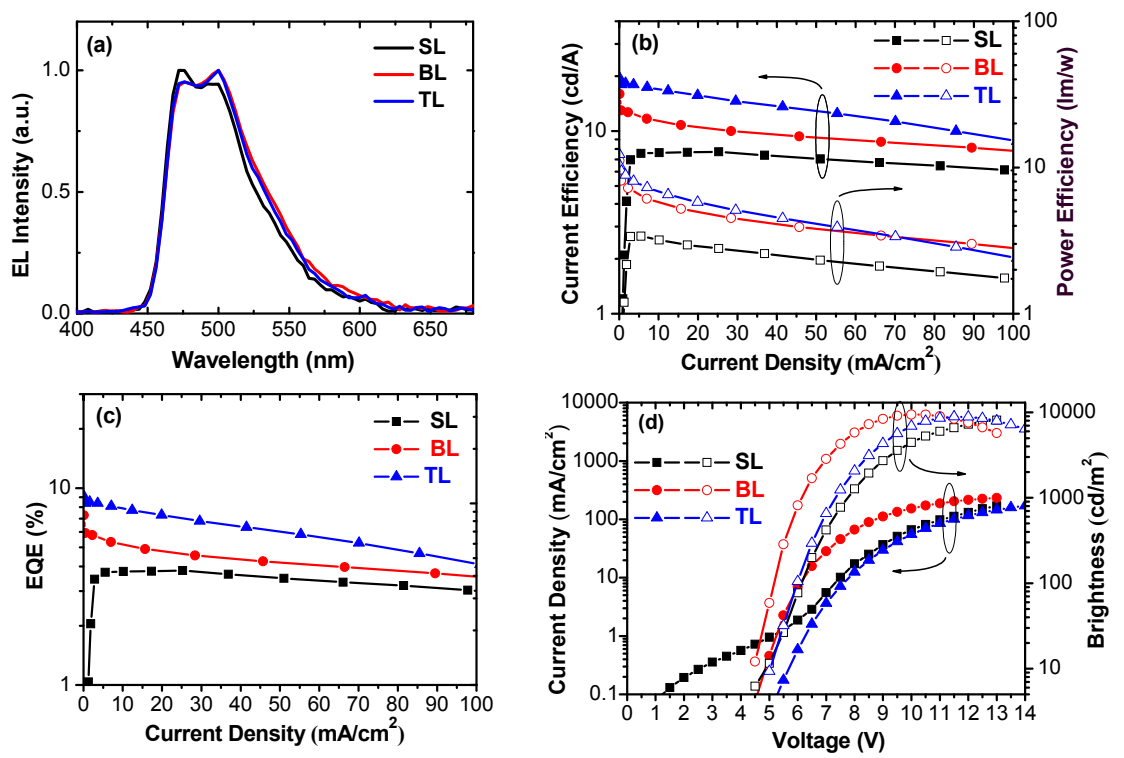

Figure 6. Electroluminescence characteristics of SimCP3-hosted FIrpic OLEDs. (a) EL spectra at $\sim 10$ volt; (b) Current density dependent current efficiency and power efficiency; (c) Current density dependent external quantum efficiency; (d) Voltage dependent current density and brightness.

Table 1. Electroluminescence characteristics of SimCP3-hosted FIrpic OLEDs.

\begin{tabular}{|c|c|c|c|c|c|c|c|}
\hline Device & $\lambda_{\max }(\mathrm{nm})$ & $V_{\text {on }}{ }^{a}(V)$ & $\mathrm{L}_{\max }{ }^{b}\left(\mathrm{~cd} / \mathrm{m}^{2}\right)$ & $C E^{c}(\mathrm{~cd} / \mathrm{A})$ & $\mathrm{PE}^{\mathrm{d}}(\mathrm{lm} / \mathrm{W})$ & $\mathrm{EQE}^{\mathrm{e}}(\%)$ & $\mathrm{CIE}_{x, y} \mathrm{f}$ \\
\hline $\mathrm{SL}$ & 472,492 & 5.0 & 8078 & $7.7,7.0,7.7$ & $3.4,3.4,3.0$ & $3.8,3.4,3.8$ & $0.15,0.32$ \\
\hline BL & 476,500 & 4.5 & 9440 & $16.0,12.7,10.8$ & $11.1,7.2,5.2$ & $7.3,5.8,4.9$ & $0.16,0.34$ \\
\hline TL & 476,500 & 5.0 & 8880 & $19.6,18.0,17.4$ & $12.3,9.5,7.3$ & $9.1,8.4,8.1$ & $0.16,0.34$ \\
\hline
\end{tabular}




\section{Materials and Methods}

\subsection{General Instrumentation}

${ }^{1} \mathrm{H}$ - and ${ }^{13} \mathrm{C}-\mathrm{NMR}$ spectra including distortionless enhancement by polarization (DEPT) were measured on a Bruker AV-400 MHz or AV-500 MHz NMR Fourier transform spectrometer (Bruker, Billerica, MA, USA) at room temperature. Elemental analyses (on a FLASHEA 1112 Series, Thermo Electron Corporation, Waltham, MA, USA), matrix-assisted laser desorption/ionization time-of-flight mass spectroscopy (MALDI-TOF MS, The New Ultraflextreme ${ }^{\mathrm{TM}}$, Bremen, Germany), and fast atom bombardment (FAB) mass spectroscopy (FAB-MS, JMS-700 double focusing mass spectrometer, JEOL, Tokyo, Japan) were performed by the Elemental Analyses Laboratory and Mass Spectroscopic Laboratory, respectively, in-house service of the Institute of Chemistry, Academic Sinica. Infrared absorption spectra were recorded on a Varian 640-IR FT-IR spectrometer (Palo Alto, CA, USA). The sample of SimCP3 was ground together with $\mathrm{KBr}$ powder and compressed into a thin disc. Thermal decomposition temperatures $\left(T_{\mathrm{d}}{ }^{\prime} \mathrm{s}\right)$ of the host materials were measured by thermogravimetric analysis (TGA) using Perkin-Elmer TGA-7 analyzer systems (Waltham, MA, USA). Melting temperatures $\left(T_{\mathrm{m}}{ }^{\prime} \mathrm{s}\right)$, crystallization temperatures $\left(T_{\mathrm{c}}^{\prime} \mathrm{s}\right)$, and glass transition temperatures $\left(T_{\mathrm{g}}{ }^{\prime} \mathrm{s}\right)$ of the host materials were measured by differential scanning calorimetry (DSC) using Perkin-Elmer DSC-6 analyzer systems (Waltham, MA, USA), using a scan rate of $10{ }^{\circ} \mathrm{C} / \mathrm{min}$. The X-ray diffraction measurement of the solution-casting thin film was carried out by using a Bruker D8 Advance diffractometer (Billerica, MA, USA) equipped with a Lynxeye detector. The radiation used was a monochromatic $\mathrm{Cu} \mathrm{K} \alpha$ bea'm of wavelength $\lambda=0.154 \mathrm{~nm}$. AFM measurements were carried out with XE-100 from Park Systems (Suwon, South Korea) using a non-contact mode to obtain topography images of the thin films, which were prepared by a spin-coating chlorobenzene solution of SimCP3 or SimCP3:FIrpic on a PEDOT:PSS-coated ITO-glass substrate. UV-visible absorption spectra were recorded on a Hewlett-Packard 8453 diode array spectrophotometer (Palo Alto, CA, USA). Room temperature fluorescence spectra were recorded on a Hitachi fluorescence spectrophotometer F-4500 (Tokyo, Japan). The ionization potentials (or HOMO energy levels) of SimCP3 were determined with a low energy photo-electron spectrometer (Riken-Keiki AC-2, Riken Keiki Co., Ltd., Tokyo, Japan). LUMO energy levels were estimated by subtracting the optical energy gap $\left(E_{\mathrm{g}}\right)$ from HOMO energy levels. $E_{\mathrm{g}}$ was determined by the on-set absorption energy from the absorption spectra of the materials as thin film. To measure the triplet energy gap $\left(E_{\mathrm{T}}\right)$ of a thin film sample, we established a system with a temperature control of Model 350 (LakeShore Company, Westerville, OH, USA) as low as $10 \mathrm{~K}$ by Model 22C/350C Cryodyne Refrigerators (Janis Research Company, Woburn, MA, USA) and a tunable laser with excitation wavelengths of 213, 266, 355, 532, and $1064 \mathrm{~nm}$ (Brilliant B laser, Quantel Company, Newbury, Berkshire, UK), which was coupled with a time-delay controller of LP920 flash photolysis spectrometer (Edinburgh Instrument, Kirkton Campus, Livingston, England). We also acquired the triplet energy gap of SimCP3 in frozen 2-Me-THF by using Fluorolog III photoluminescence spectrometer (Kirkton Campus, Livingston, UK), which was equipped a xenon lamp as excitation light source.

\subsection{Device Fabrication and Performance Measurements}

The ITO substrate was purchased from Buwon Precision Sciences (Taoyuan, Taiwan with a sheet resistance around $25 \Omega / \mathrm{sq}$ and a thickness of $100 \mathrm{~nm}$. The hole transport layer-PEDOT:PSS (CH8000)—was purchased from Sigma-Aldrich (St. Louis, MO, USA). The blue phosphorescence dopant FIrpic, the electron transport layer of TmPyPB, and the hole transport layer of TAPC were obtained commercially from Lumtec (Hsinchu, Taiwan). The indium tin oxide (ITO) substrates were pre-coated with the PEDOT:PSS hole transporting layer (HTL) and baked in the air at $150{ }^{\circ} \mathrm{C}$ for $10 \mathrm{~min}$. Blends of SimCP3 and FIrpic in chlorobenzene were spin-coated on ITO/PEDOT:PSS. The active layer was then annealed at $90{ }^{\circ} \mathrm{C}$ for $30 \mathrm{~min}$. After spin-coating the active single-layer, the TmPyPB $(50 \mathrm{~nm})$, an ultrathin $\mathrm{CsF}(2 \mathrm{~nm})$ interfacial layer, and then an aluminum cathode $(100 \mathrm{~nm})$ were 
vacuum-thermal deposited. In the triple-layer device, a thin layer ( 20 nm) of TAPC was spin-coated first on PEDOT:PSS. In this case, TAPC layer was thermally annealed at $90{ }^{\circ} \mathrm{C}$ for 10 min before spin-coating SimCP3:FIrpic. A surface profiler (Dektak 150, Veeco Instruments, Plainview, NY, USA) was used for calibrating the thickness of HTL and the active layer. After the deposition of the cathode, the devices were hermetically sealed with glass and UV-cured resins in a glove box $\left(\mathrm{O}_{2}\right.$ and $\mathrm{H}_{2} \mathrm{O}$ concentration below $0.1 \mathrm{ppm}$ ). The device's active area was $0.04 \mathrm{~cm}^{2}$ and was defined by the self-made shadow mask applied in the cathode deposition. Current density and voltage characteristics were measured by a dc current-voltage source meter (Keithley 2400, Tektronix, Beaverton, OR, USA), and the device brightness (or electroluminance, $\mathrm{cd} / \mathrm{m}^{2}$ ) and EL spectra were monitored and recorded with a spectrophotometer (PR650; Photo Research, Syracuse, NY, USA). The EQE of OLEDs was calculated from the luminance, current density, and the EL spectra, assuming the EL of the OLED is isotropic, i.e., a Lambertian emission [34].

\subsection{Materials Preparation}

All chemical and reagents were obtained from commercial suppliers and used without further purification. Solvents were purified according to the standard procedures. Unless specified condition, all reaction were performed under a nitrogen atmosphere using standard Schlenk techniques. Materials involved in OLED fabrication, 4,4'-(cyclohexane-1,1-diyl)bis $(N, N$-di- $p$-tolylaniline) (TAPC), and

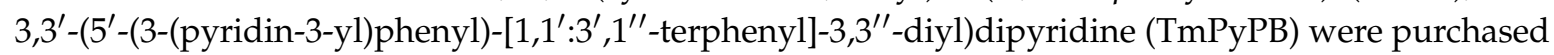
from Lumtec (Hsinchu, Taiwan) and Ultra Fine Chemical Technology Corp. (Degussa, Dusseldorf, Germany), respectively. They were used as received without further purification.

Synthesis and characterization of 9,9'-(5-Bromo-1,3-phenylene)bis(9H-carbazole), BrmCP. The synthesis and isolation of BrmCP are modified from a known procedure of a patent report [28]. To an anhydrous DMF solution $(200 \mathrm{~mL})$ containing sodium hydride (60\% suspension in oil, $13 \mathrm{~g}, 0.31$ mole), carbazole (52 g, $0.31 \mathrm{~mol}$ ) was slowly added. The mixture was stirred for $1 \mathrm{~h}$ at room temperature. After cooling in an ice bath, 3,5-difluorobromobenzene $(12 \mathrm{~mL}, 0.1 \mathrm{~mol})$ was added dropwise. The solution mixture was then heated at $130{ }^{\circ} \mathrm{C}$ for $12 \mathrm{~h}$. After cooling, an excess amount of ethanol-water mixture (10:1) was added and stirred, resulting in white precipitates. The product was isolated by suction filtration, and further purification was achieved by zone-temperature sublimation to afford white solid (44.7 $\mathrm{g}$, 92\%). ${ }^{1} \mathrm{H}-\mathrm{NMR}\left(400 \mathrm{MHz}, \mathrm{CDCl}_{3}\right): \delta(\mathrm{ppm}) 8.13(\mathrm{~d}, 4 \mathrm{H}, J=7.6 \mathrm{~Hz}), 7.85(\mathrm{~s}, 2 \mathrm{H}), 7.78(\mathrm{~s}, 1 \mathrm{H}), 7.53(\mathrm{~d}$, $4 \mathrm{H}, J=7.6 \mathrm{~Hz}), 7.45(\mathrm{t}, 4 \mathrm{H}, J=7.6 \mathrm{~Hz}), 7.32(\mathrm{t}, 4 \mathrm{H}, J=7.6 \mathrm{~Hz}) .{ }^{13} \mathrm{C}-\mathrm{NMR}\left(100 \mathrm{MHz}, \mathrm{CDCl}_{3}\right): \delta(\mathrm{ppm})$ $140.72,140.55,128.89,126.58,124.32,124.18,124.04,120.98,120.77,109.81$. MALDI-HRMS: calcd MW $486.0726, m / z=486.0705\left(\mathrm{M}^{+}\right)$.

Synthesis and characterization of $9,9^{\prime}, 9^{\prime \prime}, 9^{\prime \prime \prime}, 9^{\prime \prime \prime \prime}, 9^{\prime \prime \prime \prime \prime}-(($ phenylsilanetriyl)tris(benzene-5,1,3-triyl)) hexakis(9H-carbazole) (SimCP3). To a refluxing toluene $(4 \mathrm{~mL})$, sodium metal $(0.2 \mathrm{~g}, 8.3 \mathrm{mmol})$ was added. The mixture was stirred for $10 \mathrm{~min}$. Then, $\operatorname{BrmCP}(2.0 \mathrm{~g}, 4.0 \mathrm{mmol})$ and trichloro(phenyl)silane $(0.2 \mathrm{~mL}, 1.3 \mathrm{mmol})$ dissolved in toluene $(4 \mathrm{~mL})$ were added slowly to the refluxing toluene containing sodium metal through an additional funnel. After $3 \mathrm{~h}$ of reaction, the reaction solution was cooled to room temperature and an excess amount of methanol was added. The resulting precipitations were isolated by suction filtration and subjected to column chromatography (silica gel, dichloromethane/hexanes: 2/3). A white solid was obtained with a yield of $34 \%(0.6 \mathrm{~g})$. FT-IR $\left(\lambda, \mathrm{cm}^{-1}\right): 3044(w), 3013(w), 1623(w), 1580(s), 1490(m), 1480(m), 1447(s), 1416(m), 1374(m), 1330$ (s), $1309(\mathrm{~s}), 1227(\mathrm{~s}), 1191(\mathrm{~m}), 1155(\mathrm{~m}), 1120(\mathrm{~m}), 1098(w), 1027(w), 1002(w), 959(w), 923(w), 904$ $(w), 882(w), 840(w), 798(w), 778(w), 746(s), 706(s), 722(s)$. UV-Vis $\left(\mathrm{CH}_{2} \mathrm{Cl}_{2}\right): \lambda_{\max } 293,311,325$, $339\left(3.61 \times 10^{4} \mathrm{~cm}^{-1} \cdot \mathrm{M}^{-1}\right) .{ }^{1} \mathrm{H}-\mathrm{NMR}\left(400 \mathrm{MHz}, \mathrm{CDCl}_{3}\right): \delta(\mathrm{ppm}) 8.07-8.03(\mathrm{~m}, 18 \mathrm{H}), 7.87(\mathrm{~m}, 5 \mathrm{H})$, $7.48-7.47(\mathrm{~m}, 3 \mathrm{H}), 7.27(\mathrm{~d}, 12 \mathrm{H}, J=8.4 \mathrm{~Hz}), 7.15(\mathrm{t}, 12 \mathrm{H}, J=7.6 \mathrm{~Hz}), 7.00(\mathrm{t}, 12 \mathrm{H}, J=7.6 \mathrm{~Hz}) .{ }^{13} \mathrm{C}-$ and DEPT NMR (125 MHz, $\left.\mathrm{CDCl}_{3}\right): \delta$ (ppm) 140.54, 140.04, 137.07, 136.27 (DEPT-90), 133.69, 132.92 (DEPT-90), 131.40 (DEPT-90), 129.19 (DEPT-90), 127.27 (DEPT-90), 126.47 (DEPT-90), 123.89, 120.74 
(DEPT-90), 120.62 (DEPT-90), 109.62 (DEPT-90). MALDI-HRMS: calcd MW 1326.4800, $\mathrm{m} / \mathrm{z}=1326.4757$ $\left(\mathrm{M}^{+}\right)$. Anal. Found (calcd) for $\mathrm{C}_{96} \mathrm{H}_{62} \mathrm{~N}_{6} \mathrm{Si}$ : C 86.66 (86.85), H 4.92 (4.71), N 6.37 (6.33).

\section{Conclusions}

In summary, we have overcome the synthetic difficulty of SimCP3, an advanced homologue of previously known SimCP2. We have examined the amorphous nature and the spectroscopic properties (HOMO and LUMO energy levels as well as the triplet energy gap) of SimCP3. Three sky-blue phosphorescence OLEDs have been fabricated with a SimCP3:FIrpic light-emitting layer, which was spin-coated from solution. A trilayer device exhibits the highest EL efficiency of $\sim 9 \%, \sim 20 \mathrm{~cd} / \mathrm{A}$, or $\sim 12 \mathrm{~lm} / \mathrm{W}$, demonstrating the viability of SimCP3 as a solution-processed host material for sky-blue phosphorescence OLEDs.

Acknowledgments: We thank the Ministry of Science and Technology (MOST 103-2113-M-001-021-MY3), Academia Sinica, and National Taiwan University for financial support. We acknowledge Jiun-Haw Lee of National Taiwan University in the calculation of EQE of the OLEDs in this work.

Author Contributions: Chin-Ti Chen and Chao-Tsen Chen conceived and designed the experiments; Cheng-Lung $\mathrm{Wu}$, Yung-Ting Chang, Jan Golder, and Yi-Ting Lee performed the experiments; Yung-Ting Chang and Yi-Ting Lee analyzed the data; Chin-Ti Chen and Chao-Tsen Chen wrote the paper.

Conflicts of Interest: The authors declare no conflict of interest.

\section{References}

1. Romain, M.; Tondelier, D.; Geffroy, B.; Shirinskaya, A.; Jeannin, O.; Rault-Berthelot, J.; Poriel, C. Spiro-configured phenyl acridine thioxanthene dioxide as a host for efficient PhOLEDs. Chem. Commun. 2015, 51, 1313-1315. [CrossRef] [PubMed]

2. Romain, M.; Tondelier, D.; Jeannin, O.; Geffroy, B.; Rault-Berthelot, J.; Poriel, C. Properties modulation of organic semi-conductors based on a donor-spiro-acceptor (D-spiro-A) molecular design: New host materials for efficient sky-blue PhOLEDs. J. Mater. Chem. C 2015, 3, 9701-9714. [CrossRef]

3. Cui, J.-S.; Xie, Y.-M.; Wang, Y.-K.; Zhong, C.; Deng, Y.-L.; Liu, X.-Y.; Jiang, Z.-Q.; Liao, L.-S. Pure Hydrocarbon Hosts for $\cong 100 \%$ exciton harvesting in both phosphorescent and fluorescent light-emitting devices. Adv. Mater. 2015, 27, 4213-4217. [CrossRef] [PubMed]

4. $\quad$ Ding, L.; Dong, S.-C.; Jiang, Z.-Q.; Chen, H.; Liao, L.-S. Orthogonal molecular structure for better host material in blue phosphorescence and larger OLED white lighting panel. Adv. Funct. Mater. 2015, 25, 645-650. [CrossRef]

5. Lai, C.-C.; Huang, M.-J.; Cou, H.-H.; Liao, C.-Y.; Rajamalli, P.; Cheng, C.-H. m-Indolocarbazole derivative as a universal host material for RGB and white phosphorescent OLEDs. Adv. Funct. Mater. 2015, 25, 5548-5556. [CrossRef]

6. Huang, J.-J.; Hung, Y.-H.; Ting, P.-L.; Tsai, Y.-N.; Gao, H.-J.; Chiu, T.-L.; Lee, J.-H.; Chen, C.-L.; Chou, P.-T.; Leung, M.-K. Orthogonally substituted benzimidazole-carbazole benzene as universal hosts for phosphorescent organic light-emitting diodes. Org. Lett. 2016, 18, 672-675. [CrossRef] [PubMed]

7. Thiery, S.; Tondelier, D.; Geffroy, B.; Jeannin, O.; Rault-Berthelot, J.; Poriel, C. Modulation of the Physicochemical Properties of Donor-Spiro-Acceptor Derivatives through Donor Unit Planarisation: Phenylacridine versus Indoloacridine-New Hosts for Green and Blue Phosphorescent Organic Light-Emitting Diodes (PhOLEDs). Chem. Eur. J. 2016, 22, 10136-10149. [CrossRef] [PubMed]

8. Duan, L.; Hou, L.; Lee, T.-W.; Qiao, J.; Zhang, D.; Dong, G.; Wang, L.; Qiu, Y. Solution processable small molecules for organic light-emitting diodes. J. Mater. Chem. 2010, 20, 6392-6407. [CrossRef]

9. Zhong, C.; Duan, C.; Hung, F.; Wu, H.; Cao, Y. Materials and devices toward fully solution processable organic light-emitting diodes. Chem. Mater. 2011, 23, 326-340. [CrossRef]

10. Xiao, L.; Chen, Z.; Qu, B.; Luo, J.; Kong, S.; Gong, Q.; Kido, J. Recent progresses on materials for Electrophosphorescent organic light-emitting devices. Adv. Mater. 2011, 23, 926-952. [CrossRef] [PubMed]

11. Tao, Y.; Yang, C.; Qin, J. Organic host materials for phosphorescent organic light-emitting diodes. Chem. Soc. Rev. 2011, 40, 2943-2970. [CrossRef] [PubMed] 
12. Lee, Y.-T.; Chang, Y.-T.; Lee, M.-T.; Chiang, P.-H.; Chen, C.-T.; Chen, C.-T. Solution-processed bipolar small molecular host materials for single-layer blue phosphorescent organic light-emitting diodes. J. Mater. Chem. C 2014, 2, 382-391. [CrossRef]

13. Jiang, W.; Xu, H.; Ban, X.; Yuan, G.; Sun, Y.; Huang, B.; Duan, L.; Qiu, Y. Alcohol-soluble Electron-transport small molecule for fully solution-processed multilayer white Electrophosphorescent devices. Org. Lett. 2014, 16, 1140-1143. [CrossRef] [PubMed]

14. Aizawa, N.; Pu, Y.J.; Watanabe, M.; Chiba, T.; Ideta, K.; Toyota, N.; Igarashi, M.; Suzuri, Y.; Sasabe, H.; Kido, J. Solution-processed multilayer small-molecule light-emitting devices with high-efficiency white-light emission. Nat. Commun. 2014, 5, 5756. [CrossRef] [PubMed]

15. Tsuboi, T.; Liu, S.-W.; Wu, M.-F.; Chen, C.-T. Spectroscopic and electrical characteristics of highly efficient tetraphenylsilane-carbazole organic compound as host material for blue organic light emitting diodes. Org. Electron. 2009, 10, 1372-1377. [CrossRef]

16. Jou, J.-H.; Wang, W.-B.; Chen, S.-Z.; Shyue, J.-J.; Hsu, M.-F.; Lin, C.-W.; Shen, S.-M.; Wang, C.-J.; Liu, C.-P.; Chen, C.-T.; et al. High-efficiency blue organic light-emitting diodes using a 3,5-di(9H-carbazol-9-yl)tetraphenylsilane host via a solution-process. J. Mater. Chem. 2010, 20, 8411-8416. [CrossRef]

17. Liu, S.-W.; Yuan, C.-H.; Yeh, S.-J.; Wu, M.-F.; Chen, C.-T.; Lee, C.-C. Efficiency enhancement of solution-processed single-layer blue-phosphorescence organic light-emitting devices having co-host materials of polymer (PVK) and small-molecule (SimCP2). J. Soc. Inform. Disp. 2011, 19, 346-352. [CrossRef]

18. Liu, S.-W.; Chang, Y.-T.; Lee, C.-C.; Yuan, C.-H.; Liu, L.-A.; Chen, Y.-S.; Lin, C.-F.; Wu, C.-I.; Chen, C.-T. Single-layer blue Electrophosphorescent organic light-emitting diodes based on small-molecule mixed hosts: Comparison between the solution and vacuum fabrication processes. Jpn. J. Appl. Phys. 2013, 52, 012101. [CrossRef]

19. Chang, Y.-T.; Liu, S.-W.; Yuan, C.-H.; Ho, Y.-H.; Chen, K.-Y.; Lee, Y.-T.; Wu, M.-F.; Lee, C.-C.; Wei, P.-K.; Chen, C.-T.; et al. Comparison of light out-coupling enhancements in single-layer blue-phosphorescent organic light emitting diodes using small-molecule or polymer hosts. J. Appl. Phys. 2013, 114, 173106. [CrossRef]

20. Chang, Y.-T.; Chang, J.-K.; Lee, Y.-T.; Wang, P.-S.; Wu, J.-L.; Hsu, C.-C.; Wu, I.-W.; Tseng, W.-H.; Pi, T.-W.; Chen, C.-T.; et al. High-efficiency small-molecule-based organic light emitting devices with solution processes and oxadiazole-based electron transport materials. ACS Appl. Mater. Interfaces 2013, 5, 10614-10622. [CrossRef] [PubMed]

21. Chang, H.-W.; Lee, Y.-T.; Tseng, M.-R.; Jang, M.-H.; Yeh, H.-C.; Luo, F.-T.; Meng, H.-F.; Chen, C.-T.; Chi, Y.; Qiu, Y.; et al. General Application of blade coating to small-molecule hosts for organic light-emitting diode. Synth. Metals 2014, 196, 99-109. [CrossRef]

22. Jou, J.-H.; Chen, S.-Z.; An, C.-C.; Peng, S.-H.; Ting, T.-Y.; Shyue, J.-J.; Chin, C.-L.; Chen, C.-T.; Wang, C.-W. A wet and dry processable phosphorescent green dye based organic light-emitting diodes. Dyes Pigments 2015, 113, 341-350. [CrossRef]

23. Sun, D.; Zhou, X.; Li, H.; Sun, X.; Ren, Z.; Ma, D.; Yan, S. Multi-3,3'-bicarbazole-substituted arylsilane host materials with balanced charge transport for highly efficient solution-processed blue phosphorescent organic light-emitting diodes. ACS Appl. Mater. Interfaces 2015, 7, 17802-17810. [CrossRef] [PubMed]

24. Yeh, S.-J.; Wu, M.-F.; Chen, C.-T.; Song, Y.-H.; Chi, Y.; Ho, M.-H.; Hsu, S.-F.; Chen, C.H. New dopant and host materials for blue-light-emitting phosphorescent organic electroluminescent devices. Adv. Mater. 2005, 17, 285-289. [CrossRef]

25. Wu, M.-F.; Yeh, S.-J.; Chen, C.-T.; Murayama, H.; Tsuboi, T.; Li, W.-S.; Chao, I.; Liu, S.-W.; Wang, J.-K. The quest for high-performance host materials for Electrophosphorescent blue dopants. Adv. Funct. Mater. 2007, 17, 1887-1895. [CrossRef]

26. Bassett, E.A.; Emblem, H.G.; Frankel, M.; Ridge, D. The use of the Würtz-Fittig reaction in the preparation of organo-substituted silanes. J. Soc. Chem. Ind. 1948, 67, 177-179. [CrossRef]

27. Freiser, H.; Eagle, M.V.; Speier, J. Electric moments and structures of organosilicon compounds. II. The aromatic carbon-silicon bond. J. Am. Chem. Soc. 1953, 75, 2821-2824. [CrossRef]

28. Yabe, M.; Shiotani, T.; Sato, H.; Akiyama, S. Tetraaminobiphenyls, Their Charge Transporting or Electroluminescent Materials, and Organic Electroluminescent Devices Using Them. JP 2005047811 A, 24 February 2005. 
29. Kipping, F.S.; Sands, J.E. Organic derivatives of silicon. Part XXV. Saturated and unsaturated silicohydrocarbons, $\mathrm{Si}_{4} \mathrm{Ph}_{8}$. J. Chem. Soc. Trans. 1921, 119, 830-847. [CrossRef]

30. Miller, R.D.; Thompson, D.; Sooriyakumaran, R.; Fickers, G.N. The synthesis of soluble, substituted silane high polymer by Würtz coupling techniques. J. Polym. Sci. Part A Polym. Chem. 1991, 29, 813-824. [CrossRef]

31. Goushi, K.; Kwong, R.; Brown, J.J.; Sasabe, H.; Adachi, C. Triplet exciton confinement and unconfinement by adjacent hole-transport layers. J. Appl. Phys. 2004, 95, 7798-7802. [CrossRef]

32. Lee, J.; Chopra, N.; Eom, S.-H.; Zheng, Y.; Xue, J.; So, F.; Shi, J. Effects of triplet energies and transporting properties of carrier transporting materials on blue phosphorescent organic light emitting devices. Appl. Phys. Lett. 2008, 93, 123306. [CrossRef]

33. Su, S.-J.; Gonmori, E.; Sasabe, H.; Kido, J. Highly efficient organic blue- and white-light-emitting devices having a carrier- and exciton-confining structure for reduced efficiency roll-off. Adv. Mater. 2008, 20, 4189-4194. [CrossRef]

34. Fukagawa, H.; Shimizu, T.; Kawano, H.; Yui, S.; Shinnai, T.; Iwai, A.; Tsuchiya, K.; Yamamoto, T. Novel hole-transporting materials with high triplet energy for highly efficient and stable organic light-emitting diodes. J. Phys. Chem. C 2016, 120, 18748-18755. [CrossRef]

Sample Availability: Samples of SimCP3 are available from the authors.

(C) 2016 by the authors; licensee MDPI, Basel, Switzerland. This article is an open access article distributed under the terms and conditions of the Creative Commons Attribution (CC-BY) license (http:/ / creativecommons.org/licenses/by/4.0/). 